\title{
Personality-oriented technologies for the formation of professional and artistic competence among students-future artists of monumental painting
}

\author{
D.A. Gorbacheva ${ }^{1 *}$, E.V. Kostenko ${ }^{2}$, and V.I. Lyakh ${ }^{3}$ \\ ${ }^{1}$ Krasnodar State Institute of Culture, Krasnodar, Russia \\ ${ }^{2}$ Krasnodar State Institute of Culture, Krasnodar, Russia \\ ${ }^{3}$ Krasnodar State Institute of Culture, Krasnodar, Russia
}

\begin{abstract}
This article examines the technologies for the formation of professional and artistic competence among students - future artists of monumental painting in the context of a personality-oriented approach. This issue is directly related to improving the quality of vocational education through the introduction of relevant pedagogical technologies. It also describes the characteristic features of student-centered classes in universities with students - future artists of monumental painting. The types of pedagogical technologies of the personality-oriented approach are given. The most relevant personality-oriented technologies are considered separately, and their effectiveness (or ineffectiveness) is confirmed by a pedagogical experiment conducted with students by future artists of monumental painting of the Krasnodar State Institute of Culture. And also the study of pedagogical literature describing the experience of predecessors on this topic. The role of various pedagogical approaches in the system of higher professional education is revealed and updated, their individual elements, which are especially significant for research, are highlighted. The author compares the opinions of various scientists (both practitioners and theorists) who have studied the personality-oriented approach in education and the technologies used in the context of this approach, on the basis of which a comprehensive conclusion is drawn, reflected in the concluding part of the article.
\end{abstract}

\section{A problem statement}

Technologization and humanization of education are modern trends in pedagogical science, which set themselves the goal of studying the principles, patterns, technological approaches to the learning process and effective means of achieving educational results that meet modern educational standards. Therefore, today there is an urgent need to study personality-oriented technologies and methods of their application in the field of vocational training of students. The implementation of these technologies will allow art educational

* Corresponding author: prof-ped.gpa@mail.ru 
institutions to form a new concept, an arsenal of new tools and mechanisms for the formation of professional and artistic competence for the successful self-realization of young specialists and the enrichment of their spiritual world, the formation of their moral standards. This, as a result, contributes to a higher level of education for students - future artists of monumental painting.

\subsection{The objective of the work}

The problem of modernization of vocational education and a personality-oriented approach is reflected in the works of many domestic and foreign authors. But, despite this, today, the problem of personality-oriented technologies in the field of vocational training of students future artists of monumental painting is not sufficiently described in the scientific literature. In this connection, there is a need for deepening and expanding scientific ideas about the methods of teaching and the formation of professional and artistic competence among students of creative specialties.

This gave us the basis to build our own theoretical and practical research in such a way that, on the basis of theoretical material, present new practical data that can supplement the pedagogical base.

The following authors studied the issue of improving the quality of vocational education and introducing relevant pedagogical technologies into it: V.P. Bespalko, Yu.P. Vetrov, D.A. Gorbacheva, N.R. Turavec, A.P. Chernyavskaya, L.V. Bayborodova, M.V. Clarin, G.K. Selevko and others [1, 2, 3, 4, 5, 6]. Modern foreign scientists: K. Fleischmann, Sandars, J., Correia R., Dankbaar, M., de Jong, P, Eunice Eunhee Jang, Susanne P. Lajoie $[7,8,9]$. Such authors as V.V. Serikov, V.A. Slastenin, I.S. Yakimanskaya, E.A. Maralova, K. Rogers, G.T. Klinkov and others $[10,11,12,13]$.

This research is able to supplement the theoretical basis of the research with theoretical and practical data, theses and conceptual identifying elements that make it possible to actualize the need to solve the described problem and come to a single pedagogical consensus.

\section{Results of the research}

The personality-oriented approach is based on the recognition of the individuality, originality, value of each student and the development of a personality with its own experience and interests. This approach implies taking into account all the personal qualities of each student (cultural, ethnic, individually psychological, age, physiological, social) and depending on the student's potential, designing the dynamics of the development of each student's learning at the university. Where the primary role is played by the formation of universal human qualities: humanity, spirituality, morality, high human dignity and universal human values. In his research, the psychologist I.S. Yakimanskaya describes the concept of developmental education, the basis of which is the individuality and uniqueness of the personality, accumulating its "subjective experience". Based on its concept, each person is considered as individually unique, his creative abilities, personal and value aspiration are taken into account [14]. I.S. Yakimanskaya defines a personalityoriented approach as creating conditions for identifying the characteristics of a student as a subject, as recognizing the originality and intrinsic value of his subjective experience. For this, the pedagogical influence is built on the basis of the subjective experience of a young person [14].

Doctor of Pedagogical Sciences V.V. Serikov also says that the personality-oriented approach should assume the focus of pedagogical activity on the main goal - the 
personality of the student; fix the basic principles such as: individuality, freedom of the individual in choosing his educational trajectory, interactive learning, ethical humanistic interaction between teacher and student, building an educational process in a university focused on the formation of personal qualities of each student [10]. Based on this, V.V. Serikov describes the paradigm of a personality-oriented approach as an integral and significant link in an integral pedagogical chain, according to which all theses are implemented that imply the development of the personal potential of each subject of learning, that is, a conscious choice of goals and means of creative self-realization, as well as their manifestation of independence in the process of professional learning.

By the term "pedagogical technology" in this study, we mean the statement given by the Honored Scientist of the Russian Federation V.A. Slastenin: "the didactic process defined by tasks is logically structured, invariantly proceeding under the influence of certain pedagogical conditions and providing a predictable result, or as an integral system conceptually and practically significant ideas, principles, methods, teaching aids, which guarantees a sufficiently high level of efficiency and quality of teaching during its subsequent reproduction and replication" [15].

Thus, the personality-oriented approach implies the use of such technologies in the university, which allow the student - the future artist of monumental painting to fully realize their capabilities in professional activity in accordance with personal abilities, psychophysiological characteristics, as well as intellectual and creative potential, and as a result effective formation of professional and artistic competence.

In this article, the definition of the professional and artistic competence of future artists of monumental and decorative painting is interpreted as - "readiness to solve various problems, the amount of knowledge, skills and abilities that are necessary for the effective solution of specific problems; the ability and willingness of an individual to apply knowledge, skills and generalized methods of action, studied in the learning process, in practice, in professional activity, in a modern market economy" [16].

A personality-oriented approach implies the full development of such functions of a young person as: selectivity (the ability to make a choice); responsibility (the ability to take responsibility for their activities and their results); independence (getting rid of the influence of various factors); formative function (formation of the "I" image); reflection (the ability to comprehend their activities); beingness (search for the meaning of life and creativity); humanitarian orientation (preservation and restoration of spirituality and morality); cultural creation (preservation, reproduction and development of culture by artistic and graphic means) [10].

Doctor of Pedagogical Sciences E.A. Maralova reveals the psychological and pedagogical meaning of a university teacher in the framework of the implementation of a personality-oriented approach as one of the most important factors in the formation of a student's personal and creative position, for meaningful self-determination and for realizing his creative potential. The student himself must be a subject of actual activity, who has determined its meaning and meaning for himself, as well as a subject who independently sets tasks and chooses ways and methods to solve them [12].

Particularly interesting for our research is the idea of A.V. Khutorsky that the individual educational trajectory of a student is the most important component in the technology of applying a personality-oriented approach, when a student personifies a personal way of realizing his personal and creative capabilities [17].

Russian scientist and teacher V.V. Serikov describes the triad "task - dialogue - game" as the basis of the technology of personality-oriented learning, which makes it possible to create a "value-semantic field of intersubjective communication as an organic component of a holistic educational process. In this situation, the world of human experience is 
revealed by its other side - personal and semantic, when it is assimilated as a personal value by referring not only to memory, but also to the deep structures of consciousness" [10].

One of the general features of student-centered learning technologies is pedagogical situations, since they create circumstances that induce the student to express himself as a person. That is, they relate to such topics as: self-determination, determination of one's place in the world and society, status, recognition, understanding of vital needs.

Distinctive features of student-centered classes in universities with students - future artists of monumental painting are in the following principles:

1. Interaction "teacher-student" (subject-subject interaction). The teacher, working with students, organizes their work and creates conditions for the formation and development of their personal capabilities - the development of creative, figurative, three-dimensional, associative, abstract thinking, intelligence [12].

2. Activities of the teacher. The teacher creates situations of success for students, while students must conduct an independent search for solutions to the assigned tasks. The central figure is a student [18].

3. Student activity [12]. The activity is carried out not by the teacher, but by the student. The methods of project and problem learning are used; the formation of taste, mastery of compositional laws, visual literacy.

4. Goal-setting. The goal is to create such an educational activity that would turn the student into a subject interested in the learning process, respectively, the formation of the ability for independent educational activity, self-control, self-organization, selfgovernment; interest in the chosen profession and the inclination to engage in it [14].

Already when planning the goal, tasks of the lesson plan, highlighting the main areas of activity in the context of a personality-oriented approach, it is necessary to put the student in the foreground, and only then the activity itself [12].

The pedagogical technologies of the personality-oriented approach are subdivided into types: problem-search (the basis of such classes is reduced to the formulation of tasks in which students independently find the necessary information to solve them) [Ошибка! Источник ссылки не найден.]; activity (they consist in - the student's ability to act as a subject of activity); discussion (various types of discussions on the studied topics: discussion - dialogue, brainstorming, round table, etc.) [11]; game (the basis of this method is the modeling of problem situations, professional, creative tasks in educational practice); psychological (reduced to making an independent decision by students to perform or not a particular task) [20]; reflective (they consist in the student's ability to formulate conclusions about the work done, to realize the correctness of the solution of the assigned professional task, the efforts made and the effectiveness of the solution of professional tasks).

In the process of forming professional and artistic competence, both group and individual forms of education are used. The choice of the teaching method is mainly assigned to the teacher, he selects the most effective combination of technologies, methods, approaches, in accordance with the predetermined goals and individual characteristics of future specialists in monumental art. It is logical that his professionalism, personal characteristics, and the ability to effectively interact with students are of great importance.

The main personality-oriented technologies in modern pedagogy: - the technology of project-based teaching - is aimed at the formation of students' specific actions necessary for the implementation of professionally oriented tasks. Which implies the possession of integrated knowledge; understanding of practice, theory of professional disciplines; independent student activity; the ability to implement research methods, identify possible difficulties, set goals and propose hypotheses for their solution; formulation of the results obtained; processing and analysis of the obtained data, formulation of conclusions.

There are such types of educational projects as: simulation games; specialized practiceoriented projects; information and analytical; 
- business game technology - aimed at developing the professional behavior and thinking of students. When performing technically complex works on a monumental decorative composition, the introduction of play technologies helps to relieve tension, effectively study and analyze "living" the necessary material, and create a liberated creative space in the workshop. This method helps to form students' competencies: analysis of a specific type of tasks; collection and analysis of the required material; making decisions with incomplete or insufficiently reliable information, etc. Students are not afraid to make mistakes and learn from them, which reduces the time to master even complex skills. Through role-playing games with students, it is convenient to practice and study alternative solutions to situations outside the classroom. Effectively stimulate the involvement of students of the entire group in well-coordinated collective work on the implementation of a creative project, which contributes to the development of communication skills; activates a positive emotional mood, mental activity, which is one of the most important components in the formation of professional and artistic competence among students - future artists of monumental painting. The play technique also allows one to perceive different views on the situation. An important stage in modeling role activity is the search for a design solution for a monumental decorative object in an architectural environment. Students can participate in replicating both real and imagined conditions. It is important that the reactions and activities of the participants in the recreated situation correspond to the real situation as much as possible. This technology helps in further socialization, adaptation to environmental conditions, as well as in the development of norms and values of society, activation of a positive emotional mood. Modeling professional and industrial activities is useful in the study of complex processes, problems, when the artist of monumental painting must show empathy for the inhabitants of the city who will come into contact with the work of monumental decorative painting every day. Staged situations require taking into account many factors and variables, taking into account the humanistic values, functional and ideological purpose of the object, to find non-standard, creative solutions and predict the results [20].

- the technology of modular training - is aimed at the personality of each student and is based on an activity approach. A distinctive feature is the presentation of educational material in separate, but logically interconnected modules. These modules are aimed at achieving professional and personal results;

- the technology of multilevel education - depends on the individual characteristics, potential and personality of each student. In the course of training, the technology assumes a different degree of assimilation of the acquired knowledge, while not lower than the basic level;

- pedagogy of cooperation - a technology that has as the main idea the principles of humanism and the creative development of the student's personality. The basic principle of cooperation pedagogy is formulated - "do as I do";

- case method - aimed at analyzing and solving specific situations that are presented in the "case". The case-study method is very close to the case-study method. The case on the composition of monumental - decorative painting presents - a description of problem situations that are possible in future practice in the field of professional activity (for example, an order for the execution of a monumental decorative composition for a real object). This pedagogical technology makes it possible to prepare students for practical professional activities in the classroom. This implies the skill of problem formulation, analysis of various information and an active search for creative, non-standard approaches to solving professional problems, analysis of obvious, standard and search for the most effective, best solutions, flexible response to economic and social changes in the world [21]; 
- research technology of teaching - the essence of which boils down to the organization of students' activities for the further solution of the assigned tasks. The main goal of the research method is to teach students to see problems, as well as be able to independently set tasks. In the course of completing the assigned tasks, students must independently master the basic methods of scientific knowledge.

The fact is that, in our opinion, it is necessary to start the introduction of personalityoriented technologies with the formulation of educational tasks that determine the vector of development of the educational system. In this case, technologies in the context of a personality-oriented approach manifest themselves as a significant tool that allows the student to form the ability for self-organization, self-development, responsibility and professional reliability, the ability to identify a problem, set a goal and find a way to achieve it, that is, the qualities of a professional, often requiring non-standard creative thinking and approach. Therefore, within the framework of this study, the most logical, in our opinion, would be to conduct a survey of students - future artists of monumental painting using a questionnaire that allows us to identify the effectiveness or ineffectiveness of previously introduced personality-oriented technologies and a conceptual model of the formation of professional and artistic competence in the learning process. This questionnaire includes questions that help to identify an increase or decrease in the level of formation of professional and artistic competence, depending on the presence or absence of technologies of a personality-oriented approach in education.

The results of the questionnaire clearly demonstrate the positive and effective influence of personality-oriented technologies on the criteria for the formation of professional and artistic competence among students - future artists of monumental painting.

\section{Conclusions}

This article presents personality-oriented technologies for the formation of professional and artistic competence in students - future artists of monumental painting, both for individual and group lessons. A feature of these technologies is that they help students to acquire professionally important qualities: possession of professional knowledge; abilities and skills; the presence of special personal qualities and character traits that ensure the ability of the individual to carry out effective professional activities in the context of professional cooperation within the group.

The results obtained in the course of this study allowed us to draw a number of conclusions related to the use of personality-oriented technologies as an arsenal of new tools and mechanisms for the formation of professional and artistic competence for the successful self-realization of young specialists and the enrichment of their spiritual world, the formation of their moral standards. This, as a result, contributes to a higher level of education for students - future artists of monumental painting.

Based on theoretical and practical research, we believe that it is fair to talk about personality-oriented technologies as a tool that allows you to personalize and bring to a new level a more humane process of modernizing the system of higher professional art education.

\section{References}

1. V.P. Bespalko, The components of pedagogical technology, 85 (1989)

2. Yu.P. Vetrov, A.G. Kravchenko, The quality of professional training in a modern university: theory and practice of management, 167 (2017) 
3. D.A. Gorbacheva, Development of the creative potential of youth in socio-cultural education: an axiological approach, 180 (2016)

4. A.V. Skripkina, D.A Gorbacheva, N.R. Turavec, A.A. Gorbachev, Business Reputation and Management of the Socio-Pedagogical Image Formation of Institutions of Higher Education, Tarih kultur ve sanat arastirmalari dergisi-journal of history culture and art research, 6, 1351-1357 (2017)

5. A.P. Chernyavskaya, Technologies of pedagogical activity, 288 (2017)

6. G.K. Selevko, Pedagogical technologies on the basis of didactic and methodological improvement of UVP, Research Institute of School Technologies, 288 (2005)

7. Katja Fleischmann, Hands-on versus virtual: Reshaping the design classroom with blended learning, Arts and Humanities in Higher Education, 20, 87-112 (2021)

8. J. Sandars, R. Correia, M. Dankbaar, Twelve tips for rapidly migrating to online learning during the COVID-19 pandemic, MedEdPublish, 9(1), 82 (2020)

9. Eunice Eunhee Jang, Susanne P. Lajoie, Maryam Wagner, Zhenhua Xu, Eric Poitras, Laura Naismith, Person-Oriented Approaches to Profiling Learners in Technology, Rich Learning Environments for Ecological Learner Modeling Journal of Educational Computing Research, 55(4), 552-597 (2016)

10. V.V. Serikov, Personality-oriented education, Pedagogika, 5, 16-21 (1994)

11. V.L. Slastenin, V.L. Belovolov, E.V. Ilyenko, Personality-oriented training in the process of professional training of a specialist, Siberian Pedagogical Journal, 11, 117 $130(2008)$

12. E.A. Maralova, Development of teacher readiness for the implementation of a personality-oriented approach to teaching schoolchildren (in the PKI system), 15 (1999)

13. G.T. Klinkov, Person-oriented learning as an educational and behavioral paradigm, Balkansko nauchno obozrenie, 1(3), 35-37 (2019)

14. I.S. Yakimanskaya, Technology of personality-oriented education, 176 (2000)

15. V.A. Slastenin, Personality-oriented technologies of professional and pedagogical education, Siberian Pedagogical Journal, 1, 49-74 (2008)

16. D.A. Gorbacheva, E.V. Kostenko, Substantial bases of formation of professional and artistic competence of students-future artists of monumental painting in the process of training in higher education, The world of science, culture, and education, 6, 31-33 (2020)

17. A.V. Khutorskoy, Methodology of personality-oriented learning, 269 (2005)

18. I.N. Odarich, Project activity in the educational process of the university, Learned vector on the Balkanite, 1, 18-21 (2017)

19. D.A. Gorbacheva, E.V. Kostenko, Substantial bases of formation of professional and artistic competence of students-future artists of monumental painting in the process of training in higher education, The world of science, culture, and education, 6, 31-33 (2020)

20. E.F. Mazanyuk, A.L. Tretyakov, Game technologies as a tool of motivation and improvement of the quality of university students ' training, SHS Web of Conferences, 87 (2020)

21. O.A. Andrienko, Modern educational technologies: self-presentation technology, Modern educational technologies: technology of self-presentation, 1(3), 5-7 (2019) 